8. Halperin S, Lewis H, Blumenkranz MS, Gass DM, Olk RJ, Fine SL. Choroidal neovascular membrane and other chorioretinal complications of acquired syphilis.

Am J Ophthalmol 1989;108:554-62.

9. Kawano Y, Uraguchi K, Oono S. A case of syphilitic chorioretinitis. Folia Ophthalmol Jpn 1984;35:80-5.

10. Oikawa T. A case of submacular neovascular membranes associated with syphilitic chorioretinitis. Folia Ophthalmol Jpn 1978;29:1669-77.

11. Yagasaki T, Akiyama K, Nomura H, Awaya S. Two cases of acquired syphilis with acute central chorioretinitis as initial manifestation. Jpn J Ophthalmol 1992;36:301-9.

12. Tamesis RR, Foster CS. Ocular syphilis. Ophthalmology 1990;97:1281-7.

13. Espinasse-Berrod MA, Parent de Curzon H, Campinchi R. A case of multiple epitheliopathy associated with subretinal neovascularisation. J Fr Ophtalmol 1988;119:191-4.

14. Noordoek GT, Hermans PW, Paul AN, Schouls LM, van der Sluis JJ, van Embden JDA. Treponema pallidum subspecies pallidum (Nichols) and Treponema pallidum subspecies pertenue (CDC 2575) differ in at least one nucleotide: comparison of two homologous antigens. Microb Pathol 1989;6(1):29-42.

15. Gass DM, Braunsten RA, Chenoweth RG. Acute syphilitic posterior placoid chorioretinitis. Ophthalmology 1990;97:1288-97.

16. Witmer RH. Special types of recurring choroiditis. Ophthalmologica 1952;123:354.

\section{R. Sandhu}

Department of Ophthalmology

Stoke Mandeville Hospital

Aylesbury

Buckinghamshire, UK

\section{R. Khooshabeh}

Department of Ophthalmology

Wycombe Hospital

High Wycombe

Buckinghamshire, UK

Ramona Khooshabeh

Department of Ophthalmology

Wycombe Hospital

High Wycombe

Buckinghamshire HP11 2T, UK

Tel: $+44(0) 1494425509$

Fax: + $44(0) 1494425458$
Sir,

Late-onset capsular block syndrome: an occult cause of decreased vision in a 63-year-old pseudophakic Asian woman

A 63-year-old Indian woman underwent uneventful right phacoemulsification with intraocular lens implantation. Pre-operative assessment showed an unaided right visual acuity of $6 / 60$, improving to $6 / 18$ with pinhole testing. Fundoscopy was difficult due to poor mydriasis but showed normal fundi.

Operation details included a temporal clear corneal two-step incision, continuous curvilinear capsulorhexis aided with Provisc (Alcon) viscoelastic substance and phacoemulsification via the 'divide and conquer' technique. An Acrysof (Alcon) acrylic foldable intraocular lens was implanted and the viscoelastic substance aspirated.

The patient was discharged with an unaided right visual acuity of $6 / 12$, improving to $6 / 9$ with spectacle correction $(\mathrm{OD}-0.50 /-0.50 \times 180)$.

A year later, she reattended with decreased right visual acuity of $6 / 60$, improving to $6 / 18$ with pinhole. Anterior segment examination showed quiet pseudophakia with an anteriorly displaced intraocular lens such that the anterior surface of the intraocular lens implant optic was in apposition with the edge of the pupil. Fundoscopy was again difficult due to poor mydriasis but was normal. This was confirmed by intravenous fluorescein angiography.

Only after $30 \mathrm{~min}$ of intensive cyclopentolate and phenylephrine drop instillation could satisfactory slitlamp examination of the anterior vitreous cavity be performed, showing a posteriorly displaced fibrotic posterior capsule with anteriorly located lens implant (Fig. 1). Retinoscopy demonstrated a myopic shift (OD $-2.50 /-0.50 \times 1786 / 18)$. A diagnosis of late-onset capsular block syndrome was made and $\mathrm{Nd}$ :YAG laser posterior capsulotomy performed (Fig. 2). The lens implant returned to its normal position, with the unaided right visual acuity improving to $6 / 12(-0.50 /-0.75 \times 173$ 6/9).
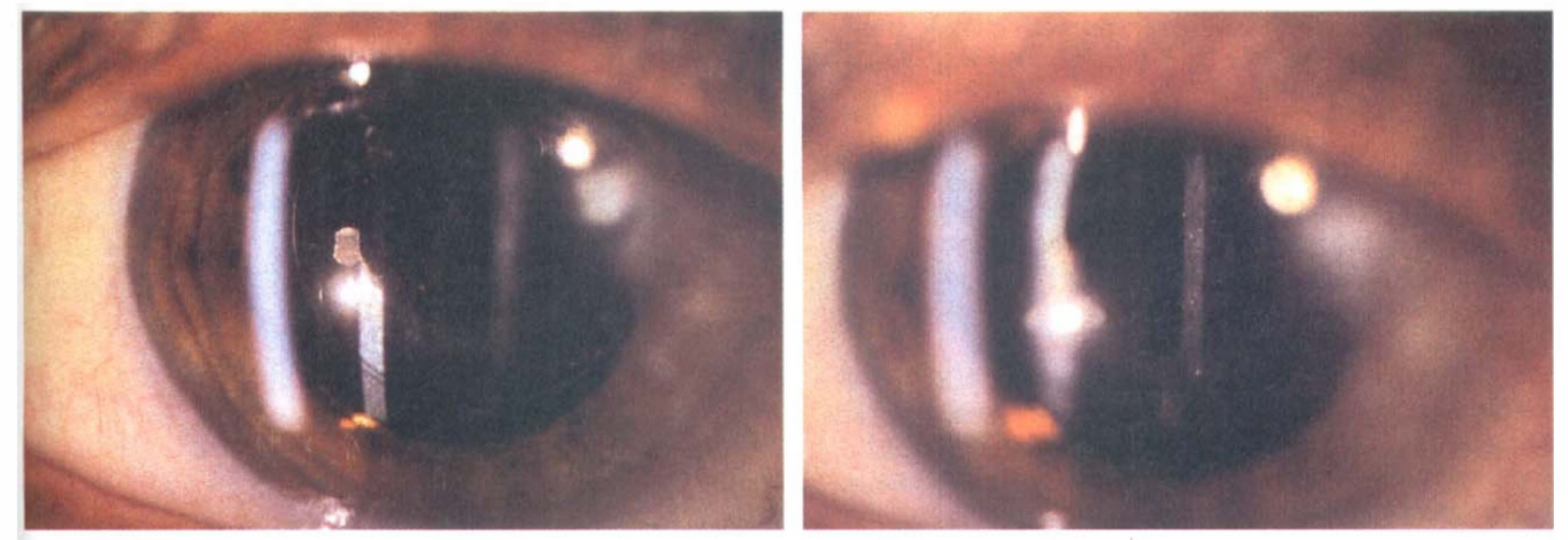

Fig. 1. Digital photographs of the anterior segment prior to Nd:YAG laser capsulotomy. The depth of field is equivalent to the distance between the cornea and the intraocular lens (IOL). Left: The posterior capsule is out of focus when focusing on the cornea. Right: The cornea is out of focus when focusing on the IOL. 


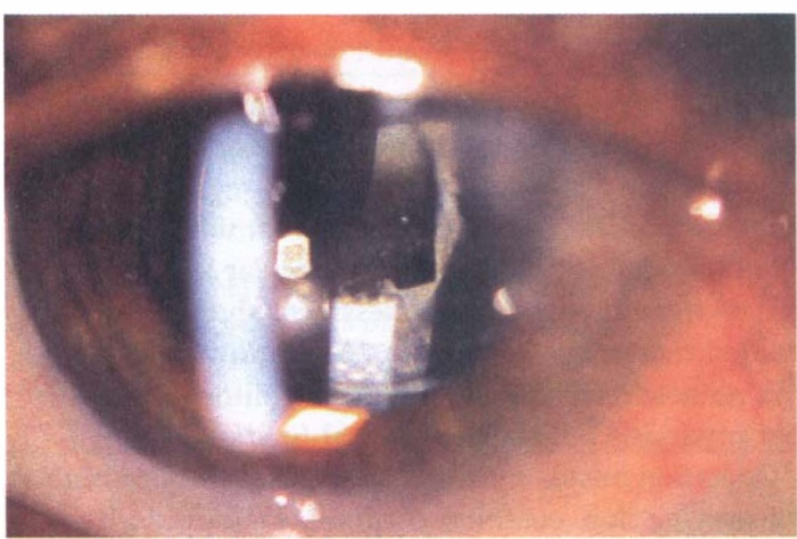

Fig. 2. Digital photograph of the anterior segment after Nd:YAG laser capsulotomy. The depth of focus is unchanged from Fig. 1. Note that the posterior capsule has now returned to the normal position and both the posterior capsule and cornea are sharply focused within the same depth of field.

Capsular block syndrome, or capsular bag distension syndrome, was first reported in $1990^{1}$ and has subsequently been classified according to the time of onset: intraoperative, early post-operative and late postoperative. ${ }^{2}$ In late-onset capsular block syndrome, residual lens epithelial cells left behind after cortical aspiration undergo metaplastic change and proliferate within the capsular bag. As well as causing posterior capsular opacification, the metaplastic cells cause the occlusion of the capsular opening by sealing off the gap between the anterior capsule and the anterior surface of the intraocular lens optic. A build-up of fluid, thought to be secreted by the lens cells, occurs within the capsular bag causing capsular distension with the subsequent anterior and posterior displacement of the intraocular lens and posterior capsule respectively. Capsulorhexisrelated lacteocrumenesia ${ }^{3}$ or liquefied after cataract ${ }^{4}$ describes the accumulation of a whitish fluid within the capsular bag. This proteinaceous fluid is also thought to be secreted by lens epithelial cells. Capsular block syndrome, although first described after continuous curvilinear capsulorhexis and phacoemulsification, has also subsequently been described after 'beercan' capsulotomy in extracapsular cataract extraction, ${ }^{5}$ and can be a subtle cause of change in refractive error after cataract surgery.

\section{References}

1. Davison JA. Capsular bag distension after endophacoemulsification and posterior chamber intraocular lens implantation. J Cataract Refract Surg 1990;16:99-108.

2. Miyake $K$, et al. New classification of capsular block syndrome. J Cataract Refract Surg 1998;24:1230-4.

3. Eifrig DE. Capsulorhexis-related lacteocrumenesia. J Cataract Refract Surg 1997;23:450-4.

4. Miyake $\mathrm{K}$, et al. Liquefied aftercataract: a complication of continuous curvilinear capsulorhexis and intraocular lens implantation in the lens capsule. Am J Ophthalmol 1998;125:429-35.

5. Cheung D, et al. Late onset crystallisation on the posterior surface of a posterior chamber lens. IOVS 1999; 40(4):(abstracts)
David Cheung

Nigel James

Department of Ophthalmology

Bradford Royal Infirmary

Bradford, UK

Mr David Cheung, Bsc (Hons), FRCOphth

Birmingham and Midland Eye Centre

Dudley Road

Birmingham B18 7QH, UK

e-mail: dmwc@bigfoot.com

\section{Sir,}

\section{Sphenoid sinus mucocoele mimicking aneurysmal} oculomotor nerve palsy

We report a case of painful oculomotor nerve palsy with pupillary involvement, which was caused by a sphenoid sinus mucocoele. Aneurysms, especially of the posterior communicating artery, are the commonest cause for a painful third cranial nerve palsy with pupillary involvement. Mucocoeles of the sphenoid sinus alone are uncommon and only a few cases causing isolated oculomotor nerve involvement have been reported. Magnetic resonance imaging (MRI) and magnetic resonance angiography proved to be non-invasive and efficient methods of investigation and prompt drainage of the mucocoele led to a complete recovery from the palsy. The optic nerve is the most frequently involved cranial nerve in sphenoid sinus mucocoeles and sudden blindness is possible. ${ }^{1} \mathrm{~A}$ clinician must have this remote possibility in mind while dealing with painful third nerve palsies.

\section{Case report}

A 71-year-old man, previously fit and well, presented to the eye casualty of our hospital with a 3 day history of severe headache and vertical diplopia. He had also noticed that his right eyelid had begun to droop. There was no history of trauma and he was not a known diabetic but was a hypertensive on treatment.

On examination, he had a partial ptosis of the right eyelid with the eyeball turned down and out. He had a dilated and unresponsive right pupil. Fundus examination and examination of the other eye was unremarkable. Hess chart demonstrated underaction of the extraocular muscles innervated by the third cranial nerve. Routine blood evaluation did not reveal any abnormality.

MRI of the brain showed diffuse high signal intensity (in axial proton density weighted and T2-weighted images) within the sphenoid sinus, which was expanded anteriorly (Fig. 1). The same mass was isointense on T1-weighted images (Fig. 2). Magnetic resonance angiography did not reveal any aneurysm in the circle of Willis.

An endoscopic sphenoethmoidectomy was performed and clear fluid and mucoid material was aspirated. No solid mass was found in the sinus. Histopathological examination confirmed the mucous nature of the aspirate and ruled out any organoid tissue or malignancy. 